\title{
Smith, B.E. with photographs by Dotter, E. (2020, 1987). Digging Our Own Graves: Coal Miners \& the Struggle over Black Lung Disease (updated edition). Haymarket Books.
}

\author{
Review by Janet Zandy
}

'Black Lung Blues'

I went to the doctor, couldn't hardly get my breath

Went to the doctor, couldn't hardly get my breath

The doctor said that you got something that well could mean your death. ${ }^{1}$

'Black lung is a cruel disease, a humiliating disease. It's when you can't do what you like to do, that's humiliating,' says a miner disabled by black lung since the age of forty-eight (p. 168).

This is a story about the bodies of coal miners in relation to power and knowledge. It is a history of the contested definition of black lung disease (actually, a cluster of diseases), of the relationship between coal dust and the human respiratory system, of the necessity for collective action, and of the struggle of coal miners and their families for compensation and for the legitimacy of their own experiential knowledge. Barbara Ellen Smith began this work as a dissertation, published it first in 1987 with Temple University Press, and then, informed by the current surge in black lung disease, revised it in 2020 for Haymarket Books.

She skillfully traces the damage to the working body by interlinking class oppressions-corporate power, deliberate governmental suppression of unionization (particularly during the Reagan era), speed-up and mechanization, bureaucratic sludge, and faulty, even biased, scientific paradigms. There's institutionalized knowledge and there's lived, endured, bodily knowledge. Which side are you on?

The title is drawn from an old Hazel Dickens song about the metaphoric 'icy cold' hand of black lung reaching for a miner's life, cold like 'water hole in the dark cave.' Black lung turns miners into living ghosts of themselves, still alive, wearing - no matter how well scrubbed - the 'mascara of the mines,' that is, black coal dust clinging to eyelids and lashes (p. 41). Literally and metaphorically, they dig their own graves.

Smith places the upsurge in (preventable) black lung disease, especially as affecting miners at a younger age and in a more virulent form, in the context of a multilayered labor history situated in geographic and political economies. Mining, at any time, is dangerous work, and increasingly hazardous with the

\footnotetext{
${ }^{1}$ Words and music: Mike Paxton, Fayette Music Co., 1969, Voices from the Mountains, Collected and recorded by Guy and Candie Carawan, Urbana: University of Illinois Press, 1982, 172.
} 
proliferation of smaller non-union mines ('dogholes') and thin seam drilling through rock sandstone with high silica content (p. 13). A retired miner from southern West Virginia describes working in a doghole: I worked at one [small, nonunion] mine. ... They really had bad equipment, old equipment, trying to get by cheap as they can, mine coal and make money (p.13).

Smith came of age as a labor historian and activist by going to West Virginia to work for the Black Lung Association in 1971-72. There she entered a world of long memories - of union battles, of ancestral labor in the mines and of danger and death. She describes this book as 'hybrid' (p. 3). It includes appendices and extensive notes, a history of the UMWA (United Mine Workers of America), especially under John Lewis, union calcification, rank and file insurrection, and the formation of the critically important, far reaching, Black Lung Association in 1969 after the November 20, 1968 mine explosion near Farmington, West Virginia which took the lives of seventy-eight miners. The Black Lung Association emerged initially out of regional organizing by both men and women, and in collaboration with a few and rare physicians. Powered by collective resistance through wildcat strikes and roving picket lines, it fueled the passage of the US Coal Mine Health and Safety Act of 1969 (p. 152). However, as Smith acknowledges, reforms have implicit limitations, and legislators, lawyers, and doctors speak languages apart from 'the class-based discontent of workers' (p. 154).

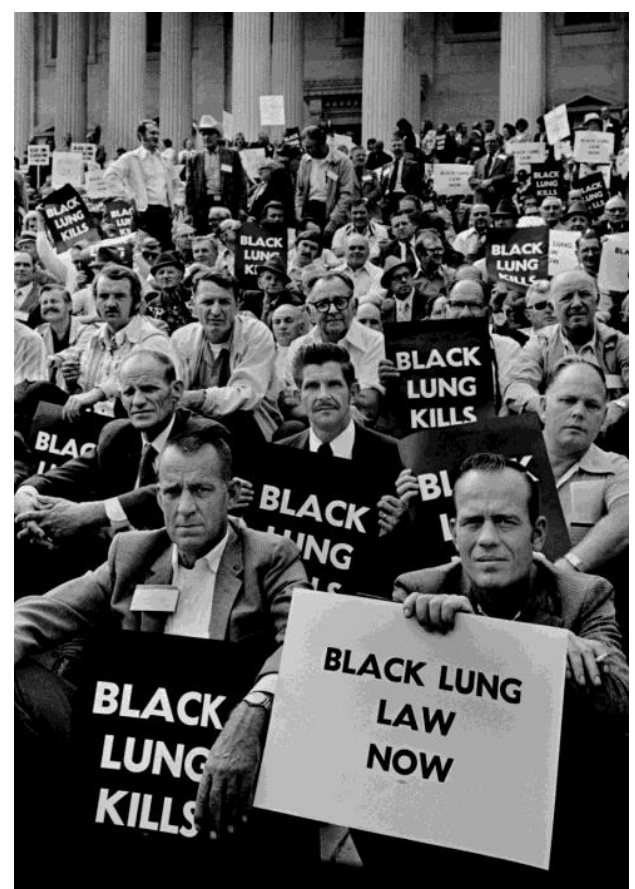

Miners protest on the steps of US Capitol, Washington D.C., 1975. Photo by Earl Dotter

This is a medical history that emphatically names the workplace as the source of disease. How that workplace is seen, and through whose eyes, is integral to perceiving the intersection of knowledge and power. Central to Smith's study are the voices of miners and their families based on interviews she conducted in the 1980s and then more recently. Those voices bring the reader inside the mine, the family home, the doctor's examining room, the very bodies of miners as they struggle to catch a clear breath, and outside to protests and strikes and to the effect of unemployment on communal networks. Here's the voice of a Black miner from southern West Virginia: 
I got laid off in '53, in November, during the Black exodus of the fifties. Everybody Black was getting cut off; it was straight out discrimination. Now, a lot of men had been cut off; many white men were cut off. But you take ten Blacks out of a community, you done stripped the whole community. I mean everyone. (p. 67).

I wish she had space for more of those voices.

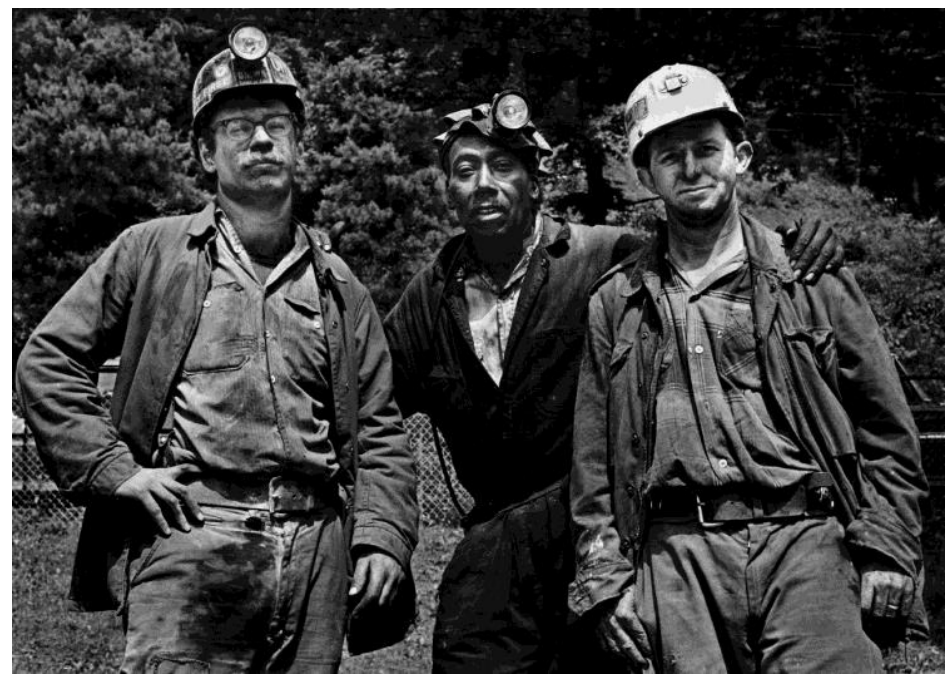

UMWA Local 6025 Safety Committee Members (left to right) Steve Shapiro and William Bennett with Jimmie Sword at Consolidation Coal's Bishop mine. Bishop, West Virginia, 1974. Photo by Earl Dotter

Smith does not flatten the story into winners and losers. She brings to the surface long-lived complex relationships among miners, unions, and operators. She acknowledges miners' desire to control their craft and work practices, their skepticism about legislative actions separate from miners' own knowledge, their disdain for 'long-haired theorists' (p. 50), their indignant conundrum in having to prove their own disease, as well as the legislative trap of shifting the conflict out of the workplace onto and within governmental bureaucracies (pp. 156-157). What is consistent is the essential contradiction between 'the necessity of earning a living wage and the need to protect themselves against dying in the effort' (p. 50).

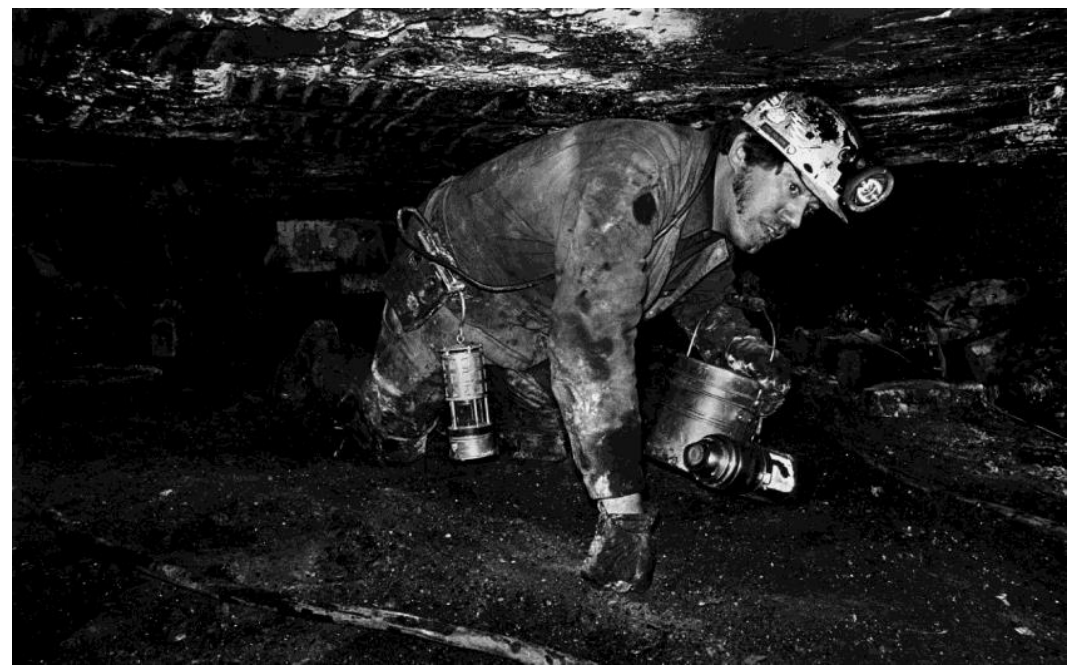




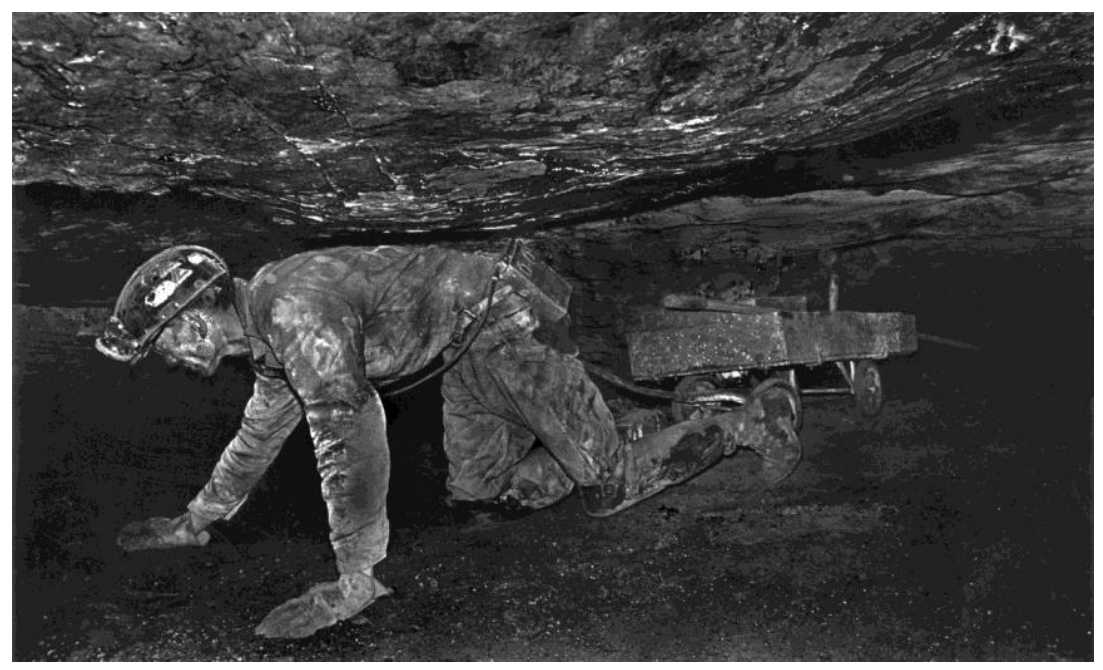

(top) Fireboss performs pre-shift inspection in 30-inch coal seam; and (bottom) using pads on his hands and knees, the shotfirer pulls a wagonload of dynamite to the coal mine face to set the explosives. Logan County, West Virginia, 1976. Photos by Earl Dotter

Digging Our Own Graves embodies the problem of measurement. It is reminiscent of Stephen Jay Gould's The Mismeasure of Man (1981) and his critique of IQ tests and intelligence ranking systems. Who or what measures how much coal dust a miner can inhale and still survive? Smith recognizes the necessity of respecting and listening to workers themselves. This is the aspect of the book that is most relevant to working-class studies in a general sense. Is the emphasis on workers or on studies? How do you get the balance right?

Definitions of black lung disease are inseparable from the diagnoses of doctors and their reliance on technological tools. Smith is cautious about science denial, ${ }^{2}$ but she has witnessed too much to separate the very defining of the disease (and consequential miners' compensation) from institutional and ideological structures of power and knowledge. The health or un-health of coal miners is inseparable from the long history of coal company doctors, from the application and reliance on X-rays for diagnosis, and for the intentional or unintentional complicity of physicians. Smith writes, 'this technological construction of disease led to a ludicrous and tragic situation throughout the coal fields: disabled miners battled for breath while physicians four hundred miles away viewed X-rays of their lungs and pronounced them free of occupational disease' (p. 168). A particularly egregious example is Dr. Paul Wheeler, a radiologist from Johns Hopkins Medical School, who read thousands of X-rays at the behest of coal companies contesting compensation claims. He concluded that scarring on miners' lungs had causations other than coal mining conditions. As a result, 'between 2000 and 2013, at least eight hundred miners were denied compensation' (p. 168). That is not the whole story, however. In the history of black lung disease there are heroic and pioneering physicians. Dr. Donald Rasmussen, for example, developed a method of identifying this complex disease (or complex of diseases) through other diagnostic tools such as blood gas analysis and the sick miners' diminished ability to oxygenate their own blood (pp. 38-39).

\footnotetext{
${ }^{2}$ See her dialogue with Chris Hamby, author of Soul Full of Coal Dust: A Fight for Breath and Justice in Appalachia, Boston: Little Brown, 2020: https://www.haymarketbooks.org/blogs/244-digging-our-own-graves-the-struggle-over-black-lungdisease-in-appalachia.
} 
In light of the current pandemic, differences and assumptions about what defines safe and unsafe work are not so evident, if they ever were. This understanding is part of the interior landscape of Earl Dotter's body of work. His images continue a visual legacy of mines and miners from Lewis Hine's 'breaker boys' to Robert Frank's Welsh miners, to Milton Rogovin's photographs of miners internationally. No one, though, gets closer to the physicality of labor than Earl Dotter. In his 32-page picture section, placed in the near center of this 2020 edition, Dotter provides a visual chronicle to accompany Smith's history. Imagine where Earl Dotter had to position his own body in order to photograph miners extracting coal miles underground. Consider the human relationships Dotter established in order to photograph within impoverished communities. Coal miners and their families trusted Earl Dotter; it is an earned trust. ${ }^{3}$

It is unlikely that coal will be back, as promised. ${ }^{4}$ What is clearly back, however, is the virulence of black lung disease. This is an essential book to understand that persistence and damage. I approach it from a position of not-knowing. True, I have meager memories of my parents shoveling coal into the cellar furnace below our four-room rented apartment in Union City, New Jersey. True, I traveled to the Black Country, Northwest of Birmingham, to have a simulated experience of going down into a mine, as well as a similar experience in Glace Bay, Nova Scotia, where you could purchase a coal replica fashioned as a pin. But I do not know hazardous work first hand. I am convinced, though, that my father would have lived longer than 49 years if he had been a professor instead of a chemical worker in a pre-OSHA plant. Those memories shape my view of a Working-Class Studies grounded in an awareness of epistemological differences. Smith's last chapter is called 'Reckonings.' There is no ultimate settling of accounts, however, but there is a way of practicing Working-Class Studies as a series of reckonings, a sorting out, a recognition of the gaps between institutional knowledge and lived, embodied, knowing.

\section{Reviewer Bio}

Janet Zandy is a Rochester Institute of Technology emerita professor. She is the author of the award winning Hands: Physical Labor, Class and Culture and other books on the working classes and culture. Her most recent book is Unfinished Stories: The Narrative Photography of Hansel Mieth and Marion Palfi, researched at the Center for Creative Photography, as an Ansel Adams Fellow. She was general editor of Women's Studies Quarterly, 1997-2001. She can be reached at janetzandy52@gmail.com.

\footnotetext{
${ }^{3}$ See Earl Dotter, The Quiet Sickness: A Photographic Chronicle of Hazardous Work in America, Fairfax, Virginia: American Industrial Hygiene Association, 1998 and Life's Work: A 50 Year Photographic Chronicle of Working in the U.S. A., Falls Church, Virginia: American Industrial Hygiene Association, 2018.

4 Eric Lipton, “The Coal Industry is Back,' Trump Proclaimed. It Wasn't,' New York Times, October 6, 2020. https://www.nytimes.com/2020/10/05/us/politics/trump-coal-industry.html\#
} 